\title{
Validation of a Low-Cost \\ Do-It-Yourself Model for Neonatal \\ Thoracoscopic Congenital Diaphragmatic Hernia Repair
}

\author{
Pedro Reino-Pires, MD, MSc, ${ }^{*}$ and Manuel Lopez, PhD ${ }^{\dagger}$ \\ *Pediatric Surgery Department, Hospital de Dona Estefânia, Lisbon, Portugal; and †Pediatric Surgery \\ Department, Hospital Universitario de Vall d'Hebron, Universidad Autónoma de Barcelona, Barcelona, \\ España
}

OBJECTIVE: We aimed to develop and validate a low cost, do-it-yourself model for neonatal thoracoscopic congenital diaphragmatic hernia $(\mathrm{CDH})$.

DESIGN: Volunteers with varying skills in neonatal minimally invasive surgery tested and evaluated the model simulating a neonatal thoracoscopic $\mathrm{CDH}$ repair. The model was built from ordinary materials purchased in a dime store: a small food container, a neoprene band simulating a diaphragm, an inflated balloon simulating a spleen, a tissue chord simulating intestine, and a body wash sponge simulating a collapsed lung. The evaluation comprised 3 sets of 5-point grading scale concerning appearance, necessary maneuvers, and ability to generate skills. Bowel reduction and suture efficacy was verified for each test.

SETTING: Minimally invasive surgery simulation room at Pediatric Surgery Department of Hospital Universitario de Vall d'Hebron, Barcelona, Spain.

PARTICIPANTS: Volunteer residents and specialists of pediatric surgery.

RESULTS: Bowel reduction was possible in every test, with 1 spleen rupture, 1 bowel entrapment, and 2 inappropriate sutures due to tension. Most volunteers considered the general endoscopic vision (63.2\%), external and internal dimensions (both $89.5 \%$ ) to be highly similar; bowel reduction (68.4\%) and diaphragm's manipulation and suture $(57.9 \%)$ to be highly or very highly similar. Regarding its ability to generate skills, most considered it to be very or extremely useful concerning: camera handling $(52.6 \%)$, working in small spaces and suture (both 100\%), and tissue

\footnotetext{
This research did not receive any specific grant from funding agencies in the public, commercial, or not-for-profit sectors.

Correspondence: Inquiries to Pedro Reino-Pires, Hospital de Dona Estefânia, Rua Jacinta Marto, 1169-045, Lisbon, Portugal; e-mail: pedro.reino.pires@gmail.com
}

handling (63.2\%). The least liked features were the colors and the diaphragm's tension. The size, portability, and the reproducibility were the most liked features.

CONCLUSIONS: We consider this low cost and easily reproducible model to be realistic enough for $\mathrm{CDH}$ repair training, having the potential to be adapted for other simulations. ( S Surg Ed I:III-UII. @ 2018 Association of Program Directors in Surgery. Published by Elsevier Inc. All rights reserved.)

KEY WORDS: surgical education, surgical simulation, congenital diaphragmatic hernia, neonatal surgery, pediatric thoracic surgery, resident education

COMPETENCIES: Medical Knowledge, Practise-Based Learning and Improvement

\section{INTRODUCTION}

The role of simulation and training in minimally invasive surgery (MIS) is becoming more important, especially regarding surgical residents' MIS skill acquisition. Simulation allows a surgeon to acquire and perfect surgical skills and is of special importance to the pediatric surgery resident, as expertise in neonatal MIS is particularly difficult to acquire. ${ }^{1}$ Indeed, simulation as a whole has been gradually acquiring a more relevant role in the MIS evolution, as reflected by the number of published papers that study technology and its ability to perfect the surgeon's technique in a simulated environment. ${ }^{2}$

Excellent validated models already exist that faithfully replicate the characteristics of tissues and anatomical structures. Specifically concerning the neonatal MIS simulation, these models exist for the congenital diaphragmatic hernia 
$(\mathrm{CDH})^{3,5}$ and esophageal atresia ${ }^{6}$ repair. However, they are not easily reproduced or acquired by a resident.

Acknowledging the importance of MIS simulation and aiming at building an easy, low cost, do-it-yourself simulator, we developed an inanimate model of thoracoscopic $\mathrm{CDH}$ repair. The incidence of $\mathrm{CDH}$ has been reported to be as high as 1 in 2000 births $^{7}$; the posterolateral Bochdalek hernia represents $90 \%$ of all cases, the left side defect being the most common. ${ }^{8}$ Some authors have established that the risk of recurrence is higher and the learning curve steeper for the thoracoscopic approach than for thoracotomy. ${ }^{9,10}$ Additionally, $\mathrm{CDH}$ has been decreasing in frequency and trainees as well as pediatric surgeons have been performing a $\mathrm{CDH}$ repair less often. ${ }^{5}$ As mentioned above, there are validated models for this repair, however as realistic as they might be we believe they are not easy to replicate. Our goal was to develop a low cost, easily built model of left posterior $\mathrm{CDH}$ that would allow a resident to develop the skills needed for a neonatal MIS procedure $(\mathrm{CDH}$ repair) regarding not only the defect and herniated abdominal content but mainly the confined work space.

\section{MATERIAL AND METHODS}

To build this model, common material from a dime store was used: a small food container with size close enough to the newborn $(900 \mathrm{~mL}$ of total volume with $18 \times 12 \times 7 \mathrm{~cm}$ of dimensions); a neoprene elastic band to simulate the diaphragm, with a defect of $2 \mathrm{~cm}$ long and $1,5 \mathrm{~cm}$ wide; a cloth cord to simulate the newborn's bowel; a small inflated balloon simulating the spleen; a body wash sponge wrapped in kitchen transparent film to simulate a collapsed lung; black spray paint; office brass fasteners (Fig. 1). The total cost for 1 simulation box and material for a great number of simulations was about $€ 11$ ( $\$ 13.25$ US).

The inner sides of the box and lid are painted with the black spray paint. Once the paint dries, 4 holes are drilled in each of the box's sides and lid in an imaginary line that divides the box in 2, transversely, and thus creating a "thoracic" and an "abdominal" cavities. Three additional holes are drilled for 2 instruments and 1 optic.

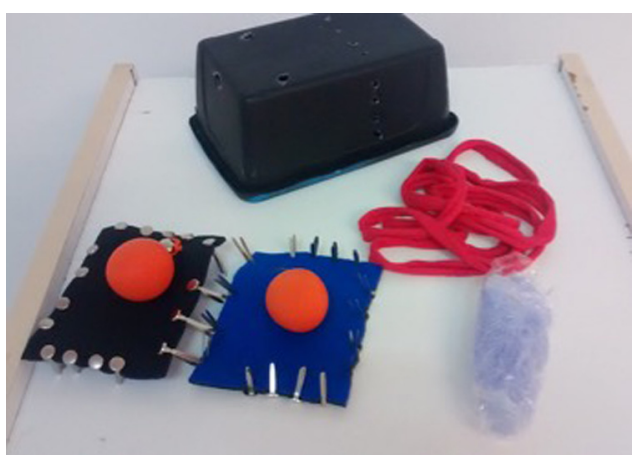

FIGURE 1. Materials used color.

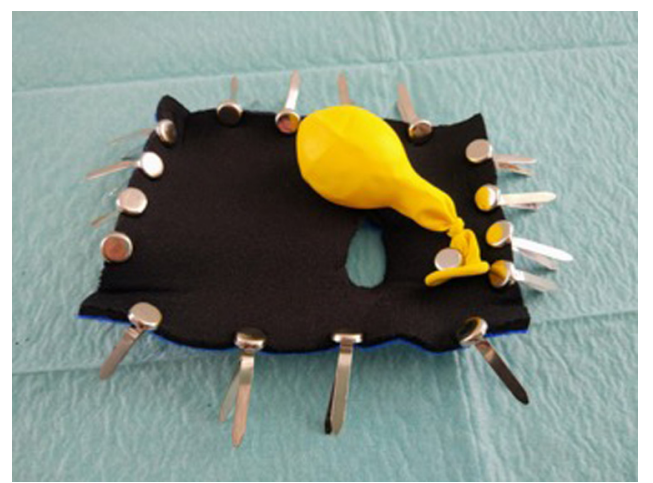

FIGURE 2. Detail: spleen attachment; brass fasteners in place for diaphragm's attachment color.

The simulated diaphragm is fixed to the box with office brass fasteners, with one of the arms passing through the elastic band. A small inflated balloon ("the spleen") is fixed on the back left of the "diaphragm" defect with a brass fastener (Fig. 2) and placed through the diaphragm's defect with the "intestine". The "lung" is placed under the herniated bowel (Fig. 3) and the remaining "diaphragm" is attached with brass fasteners to the lid as it is closed (Fig. 4). The instruments used were a $10 \mathrm{~mm} 30^{\circ}$ optic and $3 \mathrm{~mm}$ needle holder, dissector, and scissors.

Both residents and specialists of pediatric surgery tested the model. The evaluated items were: success of reduction of the abdominal content (Fig. 5), success in completing the suture (Fig. 6), and efficiency of suture (regarding a full thickness suture, gaps in the defect's closure, and abdominal content entrapment or damage).

Once the procedure was completed, the testers were asked to fill an evaluation form, divided in 3 parts. First, the volunteer experience and background were outlined by number of thoracoscopic procedures made per year and experience in neonatal thoracoscopy (novice- 0 procedures; intermediate-1-10; senior-10-20; and expert-more than 20). The volunteers were also asked to list the existing limitations in performing MIS neonatal procedures in their institution. The second part consisted of three sets of 5-point rating scale items in order to rate the model for its appearance, necessary maneuvers and ability to generate skills. Each set subsection was defined as: (1) Appearanceexternal dimensions, internal dimensions of the working area, general aspect of the endoscopic view; (2) Necessary maneuvers - reduction of the herniated abdominal content, diaphragm's manipulation and suture, box's stiffness simulating costal bones; and (3) Ability to generate skills - camera handling, maneuvering in closed spaces, suture, tissue handling. The scale defined for the first 2 sets of parameters was "No similarity, Low degree of similarity, Moderate similarity, High degree of similarity, Very high degree of similarity," and for the latter set "Useless, Almost useless, Quite useful, Very useful, Extremely useful.” After each rating, volunteers could make a small optional remark. In 


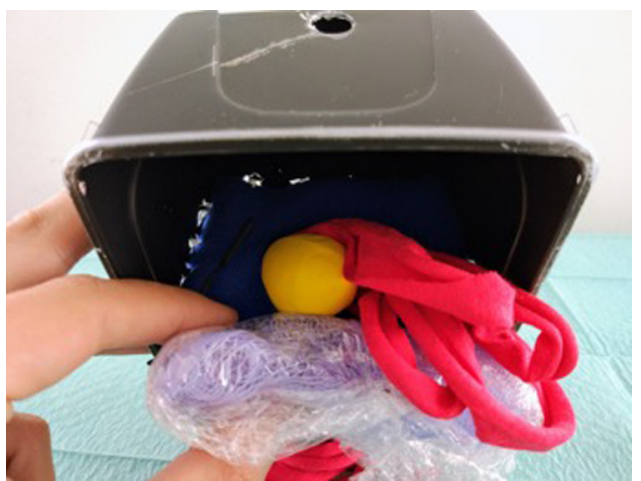

FIGURE 3. Detail: diaphragm attached, with herniated spleen and bowel, lung underneath color.

the third part of the inquiry, volunteers were asked what they liked the most and the least of the model and were able to express their open opinion and suggestions.

\section{RESULTS}

The model was evaluated by 19 testers. The tester's experience, by thoracoscopic procedures per year, was outlined as: 6 novices, 7 intermediates, 2 seniors, and 4 experts (31.6\% vs $36.8 \%$ vs $10.5 \%$ vs $15.8 \%)$. Considering neonatal thoracoscopic procedures, their experience was defined as: 12 novices, 4 intermediates, 1 senior, and 2 experts (63.2\% vs $21.1 \%$ vs $5.3 \%$ vs $10.5 \%)$. The volunteers listed the limitations toward the neonatal MIS in their institution as (more than 1 option could be selected): personal training (15), department's expertise regarding neonatal thoracoscopy (9), number of personal cases (9), instrumental (6), and bad therapeutic option (1). Of all, 3 volunteers also listed anesthesiologist's collaboration as a limitation in the free text section of the survey.

All volunteers were able to perform the bowel reduction, with 1 spleen lesion identified. A complete suture was performed in all cases, either continuous or simple; 2 sutures were identified as inappropriate due to poor tension. There was 1 case of bowel entrapment.

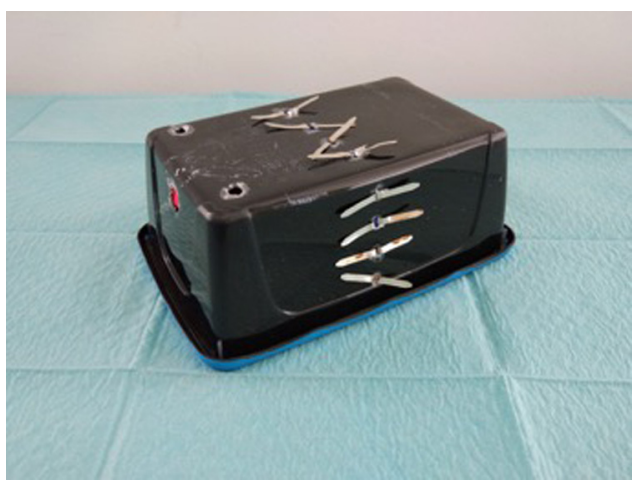

FIGURE 4. Detail: external view of a ready to use model color.
As mentioned above, the model was rated by 3 sets of parameters, using a 5-point rating scale. The results of the survey of all volunteers can be appreciated in Table 1 . The results shown in Table 2 exclude novices.

The volunteers' opinions on the most and least likeable features of the model and their suggestions were analyzed. In summary, the most common flaw specified were the colors of the material. There were also comments concerning the tissues' physical properties, namely the diaphragm and the spleen's thickness and elasticity, as well as regarding the instrumental tough entry and manipulation through the box wall. The volunteers mentioned the size, portability, low cost, and the fact that it is easily reproducible as the most liked features, describing the model as easy to build and realistic enough to be valuable in training.

\section{DISCUSSION}

We consider MIS simulation highly valuable for a surgeon's training, in every stage of a surgeon's life. It is useful for learning new approaches and techniques as well as to perfect them. In our opinion, it is of great importance in neonatal MIS, due to the patient's and procedure's characteristics as well as the small number of cases. Concerning the $\mathrm{CDH}$ repair, we believe the thoracoscopic approach to be a valid indication. When compared to the laparoscopic approach, the thoracic positive pressure created by the pneumothorax actually facilitates reduction of the herniated abdominal bowel and helps maintain it in an intra-abdominal position. Technically we consider the confined working space to be the main obstacle in the procedure, as well as the thorax rigidity due to the presence of the ribcage as another difficulty factor. Several papers have shown that there is an increased risk of recurrence with this approach and believe it to be related to the procedure's learning curve. ${ }^{9,10}$ Moreover, if we also consider the gradual lower number of $\mathrm{CDH}$ repairs performed either by trainees or by specialists, ${ }^{5}$ we can assume MIS simulation of the $\mathrm{CDH}$ repair in the neonatal setting is of greater importance.

Bearing in mind these characteristics and considerations, our goal was to build and validate a very low cost, do-ityourself, easily reproducible model that mainly aims to simulate the maneuvers and working space found in a thoracoscopic $\mathrm{CDH}$ repair. Furthermore, we designed it to be considered as a tool for a surgeon's MIS technical evolution. For those reasons, some of the material's less realistic visual features were ruled out as an obstacle, since we sought to limit the model's cost under $€ 20$ (\$24.10 US).

The sample in this study fulfils our requirements, although it would be preferable if it comprised more experienced surgeons. The top 2 limitations for performing neonatal MIS appointed by the volunteers concerned personal or general training of departmental staff, thus 


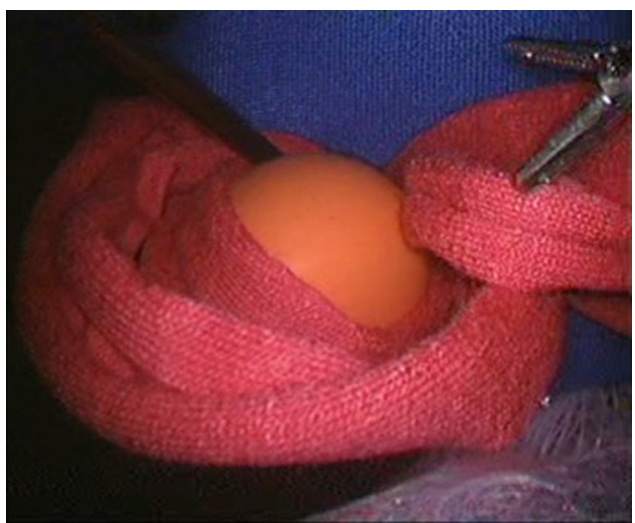

FIGURE 5. Endoscopic image of spleen and partially reduced bowel color.

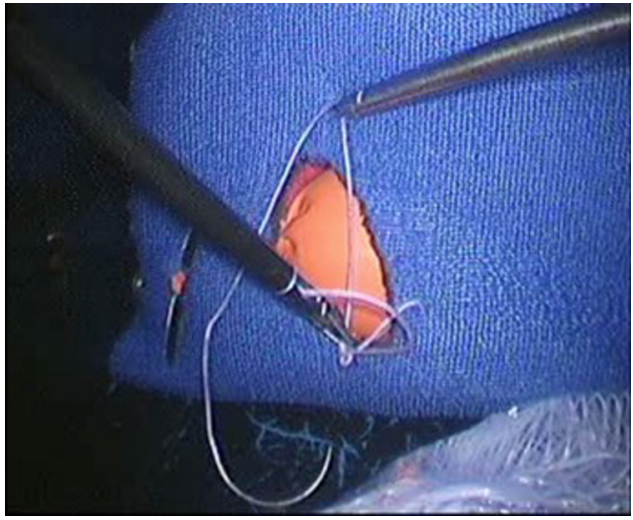

FIGURE 6. Endoscopic view of defect during suture color. emphasizing the importance of simulation. The majority of the procedures were satisfactorily completed.

In a simple evaluation of our inquiry answers (Tables 1 and 2), we conclude that this model achieves the goals set for its development. A great number of the volunteers believe it to have a high degree of similarity in terms of appearance and maneuvers necessary to complete the procedure and find the model to be very useful in its abilities to generate skills. In fact, $89.5 \%$ of the volunteers considered the model to have high or very high similarity in terms of external and internal dimensions. A $63.2 \%$ considered the general aspect of the endoscopic vision to be highly or very highly similar. Regarding maneuvers, $68.4 \%$ considered the reduction of herniated abdominal content to have high or very high similarity, $57.9 \%$ for diaphragm's manipulation and suture, and $47.4 \%$ for the box's stiffness as simulating the ribcage. Fifty two percentage of the volunteers considered the model to be very or extremely useful in generating skill for camera handling, 100\% for maneuvering in small working spaces as well as for suture, and $63.2 \%$ for tissue handling. All volunteers had seen this procedure at their institution and had some form of MIS experience, although most lacked neonatal thoracoscopic experience. Therefore, we value the opinion of the novice surgeon specially regarding the model's ability to generate MIS skills, since he is the main target for this simulator. However, for the single purpose of validating this model, we also analyzed the survey excluding the novices. In this more restrict evaluation, most of the volunteers considered the model to have a high or very high degree of similarity regarding: external dimensions (71\%), internal dimensions $(100 \%)$, endoscopic view $(71 \%)$; reduction of the herniated content $(71 \%)$, and diaphragm's manipulation (47\%). As for the ability to generate

TABLE 1. Survey Response From All Volunteers $(n=19)$

$$
n=(\%)
$$

\begin{tabular}{|c|c|c|c|c|c|}
\hline & \\
\hline & $\begin{array}{l}\text { No } \\
\text { Similarity }\end{array}$ & $\begin{array}{c}\text { Low Degree of } \\
\text { Similarity }\end{array}$ & $\begin{array}{l}\text { Moderate } \\
\text { Similarity }\end{array}$ & $\begin{array}{l}\text { High Degree of } \\
\text { Similarity }\end{array}$ & $\begin{array}{l}\text { Very High Degree } \\
\text { of Similarity }\end{array}$ \\
\hline $\begin{array}{l}\text { Appearance } \\
\text { External dimensions } \\
\text { Internal dimensions } \\
\text { Endoscopic view } \\
\text { Necessary maneuvers }\end{array}$ & $\begin{array}{l}0(0) \\
0(0) \\
0(0)\end{array}$ & $\begin{array}{ll}0 & (0) \\
0 & (0) \\
1 & (5)\end{array}$ & 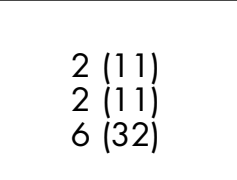 & $\begin{array}{l}15(79) \\
14(74) \\
11(58)\end{array}$ & 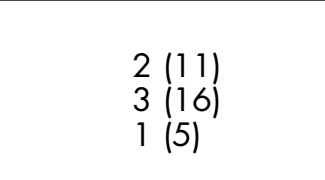 \\
\hline $\begin{array}{l}\text { Herniated abdominal content } \\
\text { reduction }\end{array}$ & $0(0)$ & $0(0)$ & $2(29)$ & $11(58)$ & $2(11)$ \\
\hline $\begin{array}{l}\text { Diaphragm's manipulation } \\
\text { and suture }\end{array}$ & $0(0)$ & $2\left(\begin{array}{ll}1 & 1)\end{array}\right.$ & $3(43)$ & $10(53)$ & $1(5)$ \\
\hline \multirow{2}{*}{$\begin{array}{l}\text { Model's box stiffness } \\
\text { simulating costal bones }\end{array}$} & $0(0)$ & $1(5)$ & $3(43)$ & $7(37)$ & $2(11)$ \\
\hline & Useless & Almost useless & Quite useful & Very useful & Extremely useful \\
\hline $\begin{array}{l}\text { Ability to generate skills } \\
\text { Camera handling } \\
\text { Maneuvering in closed } \\
\text { spaces }\end{array}$ & $\begin{array}{l}0(0) \\
0(0)\end{array}$ & $\begin{array}{l}5(26) \\
0(0)\end{array}$ & $\begin{array}{l}1(14) \\
0(0)\end{array}$ & $\begin{aligned} 8(42) \\
11(58)\end{aligned}$ & $\begin{array}{l}2(1) \\
8(42)\end{array}$ \\
\hline $\begin{array}{l}\text { Suture } \\
\text { Tissue handling }\end{array}$ & $\begin{array}{l}0(0) \\
0(0)\end{array}$ & $\begin{array}{ll}0 & (0) \\
1 & (5)\end{array}$ & $\begin{array}{l}0(0) \\
0(0)\end{array}$ & $\begin{array}{l}7(37) \\
6(32)\end{array}$ & $\begin{array}{r}12(63) \\
6(32)\end{array}$ \\
\hline
\end{tabular}


TABLE 2. Survey Responses Excluding Novices $(n=7)$

$$
n=(\%)
$$

\begin{tabular}{ccccc}
\hline No & Low Degree of & $\begin{array}{c}\text { Moderate } \\
\text { Similarity }\end{array}$ & $\begin{array}{c}\text { High Degree of } \\
\text { Similarity }\end{array}$ & $\begin{array}{c}\text { Very High Degree } \\
\text { of Similarity }\end{array}$ \\
\hline
\end{tabular}

\section{Appearance}

External dimensions

$0(0)$

0 (0)

$0(0)$

2 (29)

$0(0)$

Internal dimensions

0 (0)

$0(0)$

2 (29)

$4(57)$

$6(86)$

4 (57)

1 (14)

Necessary maneuvers

$0(0)$

$0(0)$

2 (29)

4 (57)

$1(14)$

Herniated abdominal content

0 (0)

0 (0)

$3(43)$

0 (0)

$1(14)$

Diaphragm's manipulation

0 (0)

1 (14)

$3(43)$

2 (29)

Model's box stiffness simulating costal bones

Useless Almost useless Quite useful

Ability to generate skills

Camera handling

Maneuvering in closed spaces

Suture

Tissue handling

$\begin{array}{lll}0(0) & 2(29) & 1(14) \\ 0(0) & 0(0) & 0(0) \\ 0(0) & 0(0) & 0(0) \\ 0(0) & 0(0) & 0(0)\end{array}$

$2(29)$

$3(43)$

$2(29)$

$4(57)$
$2(29)$

4 (57)

$5(71)$ skills, most of these volunteers considered it to be very or extremely useful: maneuvering in closed spaces (100\%), suture $(100 \%)$, tissue handling $(100 \%)$. The 2 aspects that did not get the response we would like were the similarity regarding the stiffness of the box while simulating the stiffness of the rib cage and the ability to generate skill in camera handling.

The scale used for this study is a self-generated scale, not a validated Linkert-type scale. We opted for this scale since we believe it is focused on our model's goals. Even though our scale lacks a clear neutral response, it is based in a bipolar scaling method. As we analyze the surveys, most of the responses were unequivocally in the positive side of the scale. For that reason, we believe this study validates the usability of this low-cost, do-ityourself, easily replicated model.

There are several aspects that can be improved in the model, especially regarding the main flaws pointed by the volunteers. The color can be changed by simply painting the structures, choosing the material in other colors, or even changing the material, although that could mean extra cost. While the neoprene band was considered to be a good choice giving a realistic sensation in its manipulation and passage of the needle, it was also referred to be too rigid, forcing the suture to be performed with more tension that in an actual diaphragm. This could be improved by replacing the neoprene by a rubber band with more plasticity, although it might be more difficult to acquire and more expensive. Even so, the system is already built, so one can experiment with different types of material and use what suits him the best. One other aspect prone to improvement is the inflated balloon that simulates the spleen. As suggested by a volunteer, the weight and density of our simulated spleen may be enriched by filling the balloon with a low-density powder such as flour.
Ultimately one can use the model to, for example, simulate an abdominal approach for the $\mathrm{CDH}$ repair or even enlarge the defect in order to simulate the diaphragmatic defect closure using a patch. Also, one can reutilize the box in order to simulate other confined working space procedures. As a whole, this simulator is an excellent tool to simulate neonatal MIS skills, namely maneuvering and suturing in tight spaces, which is crucial in other procedures such as Nissen fundoplication, duodenal atresia repair, Hirschsprung disease, anorectal malformation, among other examples.

This study shows that this simple model is reproducible and realistic enough to simulate a neonatal thoracoscopic $\mathrm{CDH}$ repair. Additionally, it can be perceived as a platform prone to modification as one sees fit, having the potential to be used for other simulations. Therefore, with these characteristics and considering its low cost, easy built features, and access to materials, this model is a good tool for every pediatric surgeon and a general contribution to pediatric surgery simulation.

\section{ACKNOWLEDGMENTS}

The authors would like to thank all the volunteers that contributed to this study as well as Aline Vaz-Silva and Teresa Bastos for their review.

Pedro Reino-Pires would like to thank Dr. João Pascoal, Director of the Pediatric Surgery Department of Hospital de Dona Estefânia for his support.

\section{REFERENCES}

1. Esposito C, Escolino M, Saxena A, et al. European society of pediatric endoscopic surgeons (ESPES) guidelines for 
training program in pediatric minimally invasive surgery. Pediatr Surg Int. 2015;31(4):367-373. http://dx.doi.org/ 10.1007/s00383-015-3672-5.

2. Partridge RW, Brown FS, Brennan PM, Hennessey IAM, Hughes MA. The LEAP ${ }^{\mathrm{TM}}$ gesture interface device and take-home laparoscopic simulators: a study of construct and concurrent validity. Surg Innov. 2016;23(1):70-77. http://dx.doi.org/10.1177/ 1553350615594734 .

3. Obata $S$, Ieiri $S$, Uemura $M$, et al. An endoscopic surgical skill validation system for pediatric surgeons using a model of congenital diaphragmatic hernia repair. 150527123733002. J Laparoendosc Adv Surg Tech. 2015;25(9). http://dx.doi.org/10.1089/lap.2014.0259.

4. van der Aa JE, Schreuder HWR. Training laparoscopic skills at home: residents' opinion of a new portable tablet box trainer. Surg Innov. 2016;23(2):196-200. http://dx.doi.org/10.1177/1553350615610654.

5. Barsness KA, Rooney DM, Davis LM. The development and evaluation of a novel thoracoscopic diaphragmatic hernia repair simulator. J Laparoendosc $A d v$ Surg Tech A. 2013;23(8):714-718. http://dx.doi.org/ 10.1089/lap.2013.0196.
6. Maricic MA, Bailez MM, Rodriguez SP. Validation of an inanimate low cost model for training minimal invasive surgery (MIS) of esophageal atresia with tracheoesophageal fistula (AE/TEF) repair. J Pediatr Surg. 2016;51(9):1429-1435. http://dx.doi.org/10.1016/ j.jpedsurg.2016.04.018.

7. Langham MR Jr., Kays DW, Ledbetter DJ, Frentzen B, Sanford LL, Richards DS. Congenital diaphragmatic hernia. Epidemiology and outcome. Clin Perinatol. 1996;23(4):671-688. Available at: http://www.ncbi. nlm.nih.gov/pubmed/8982563.

8. Torfs CP, Curry CJ, Bateson TF, Honoré LH. A population-based study of congenital diaphragmatic hernia. Teratology. 1992;46(6):555-565. http://dx.doi. org/10.1002/tera.1420460605.

9. Fujishiro J, Ishimaru T, Sugiyama M, et al. Minimally invasive surgery for diaphragmatic diseases in neonates and infants. Surg Today. 2016;46(7):757-763. http://dx. doi.org/10.1007/s00595-015-1222-3.

10. Lansdale N, Alam S, Losty PD, Jesudason EC. Neonatal endosurgical congenital diaphragmatic hernia repair. Ann Surg. 2010;252(1):20-26. http://dx.doi. org/10.1097/SLA.0b013e3181dca0e8. 